\title{
Kinetics and mechanism of catalytic oxidation of sodium ethyl mercaptide with microfluidics
}

\author{
Linjing Jiang ${ }^{1}$, Qi Chen ${ }^{1}$, Mingyu Liu ${ }^{1}$, Jiqin $\mathrm{Zhu}^{1}$, Le $\mathrm{Du}^{1}$, and Yujun Wang ${ }^{2}$ \\ ${ }^{1}$ Beijing University of Chemical Technology College of Chemical Engineering \\ ${ }^{2}$ Tsinghua University Department of Chemical Engineering
}

September 24, 2021

\begin{abstract}
Catalytic oxidation desulfurization of gasoline is a key process for the utilization of petroleum hydrocarbons. However, the inherent mechanism still remains unclear and the kinetic investigation is usually performed in processes with limited mass transfer rates. Herein, the kinetics and mechanism of catalytic oxidation of sodium ethyl mercaptide were investigated with microfluidics. On the basis of eliminating mass transfer resistance, the effects of temperature, pressure, residence time, and gas-liquid flow ratio on the oxidation were assessed. According to the results of UV-vis spectra and binding constant, it was confirmed that the catalytic center was in the form of dimer. A heterogeneous reaction kinetic model was proposed as such. The kinetic parameters close to intrinsic kinetics and corresponding kinetic rate expression were obtained.
\end{abstract}

\section{Hosted file}

AIChE-manuscript-20210805.docx available at https://authorea.com/users/435161/articles/ 538372-kinetics-and-mechanism-of-catalytic-oxidation-of-sodium-ethyl-mercaptide-withmicrofluidics 